\title{
Bilateral Fracture of the Base of the Fifth Metatarsal. A Case Report and Review of the Literature
}

\section{Mahamadou Diallo ${ }^{*}$, Layes Toure ${ }^{2}$, Louis Traoré ${ }^{3}$, Abdoul Kadri Moussa ${ }^{3}$, Seydina Alioune Beye ${ }^{4}$, Mosséré Camara5 , Mahamadou Kane1, Tiéman Coulibaly ${ }^{3}$}

${ }^{1}$ Orthopedic-Trauma Service, Nianankoro Fomba Hospital, Ségou, Mali

${ }^{2}$ Orthopedic-Trauma Service, Sikasso Hospital, Sikasso, Mali

${ }^{3}$ Orthopedic-Trauma Service, Gabriel Touré Hospital, Bamako, Mali

${ }^{4}$ Anesthesia-Resuscitation Service, Nianankoro Fomba Hospital, Ségou, Mali

${ }^{5}$ Medical Imaging Service, Nianankoro Fomba Hospital, Ségou, Mali

Email: ^diallo_mohamed67@yahoo.fr

How to cite this paper: Diallo, M., Toure, L., Traoré, L., Moussa, A.K., Beye, S.A., Camara, M., Kane, M. and Coulibaly, T. (2020) Bilateral Fracture of the Base of the Fifth Metatarsal. A Case Report and Review of the Literature. Surgical Science, 11, 32-38. https://doi.org/10.4236/ss.2020.112005

Received: January 15, 2020

Accepted: February 25, 2020

Published: February 28, 2020

Copyright (c) 2020 by author(s) and Scientific Research Publishing Inc. This work is licensed under the Creative Commons Attribution International License (CC BY 4.0).

http://creativecommons.org/licenses/by/4.0/

\begin{abstract}
We report an unusual case of basic bilateral fracture of fifth metatarsals in a 48 years old post-menopausal woman. She had previously been treated for arterial high blood pressure, parathyroidectomy and rheumatoid arthritis by a long corticotherapy treatment. The lesion was caused by an indirect mechanism in an overweight context. The diagnosis of a pseudarthrosis of the base of the fifth metatarsals was maintained after 7-month treatment. The patient received a treatment of both pseudarthrosis. The post-operative periods were simple. After a 9-month follow-up, the treatment allowed consolidation with painless feet allowing her to resume work.
\end{abstract}

\section{Keywords}

Fracture, Bilateral, Fifth Metatarsal

\section{Introduction}

The fracture of the base of the fifth metatarsal constitutes a traumatic lesion frequently encountered [1]. In recent literature it is recognized that the fifth metatarsal is most often fractured during a trauma than the other metatarsals [2] [3].

The fracture of the base of the fifth metatarsal includes the Jones fracture described by Sir Robert Jones in 1902, the avulsion fracture affecting the styloid process and the more distal stress fracture located at the diaphyseal level [4]. The etiology is very varied. When it is linked to stresses, depending on its intensity, 
the resulting fracture is classified into two types: stress fractures and insufficiency fractures [5] [6]. The crude nature of the clinical signs resulting from stress-linked fractures and the habit of some of our patients to solicit first traditional therapists often delay diagnosis. Their therapeutic management of this kind of fracture remains controversial but depends essentially on the level of physical activity and the age of the patients. The Jones fracture is characterized by an often long healing time and a relatively high frequency of non-union [4]. Its occurrence in fragile bone is a rare entity. We report an exceptional case of bilateral fracture of the base of the fifth metatarsal on a site of osteoporomalacia.

\section{Observation}

Ms. FC, teacher, 48 years old, with a history of high blood pressure, parathyroidectomy for goiter (for 3 years) and rheumatoid arthritis treated with corticosteroid therapy (14 months) consulted for a fibular pain of both feet. She had been suffering for about 7 months following a minimal trauma by a false step to the right in a context of overweight. The mechanism was indirect with a forced inversion type, the forefoot being fixed to the ground and the heel raised. This pain was chronic, aggravated by physical activity and reduced at rest. Ms FC has been followed by a traditional healer. Physical examination found a discrete swelling on the fibular edge of both feet with exquisite pain points opposite the base of the fifth metatarsals (Figure 1). The neurovascular examination was without particularity. The radiographic incidences of the front and profile of the feet made it possible to object to a rupture of the two cortices with widening of the fracture line due to bone resorption (Figure 2). The spinal canal was obstructed. These lesions were confirmed by computed tomography (Figure 3 ). The diagnosis of tight pseudarthrosis on the left and loose on the right of the base of the fifth metatarsal was retained. The patient underwent bilateral pseudarthrosis treatment. She was installed in supine position on an ordinary table,
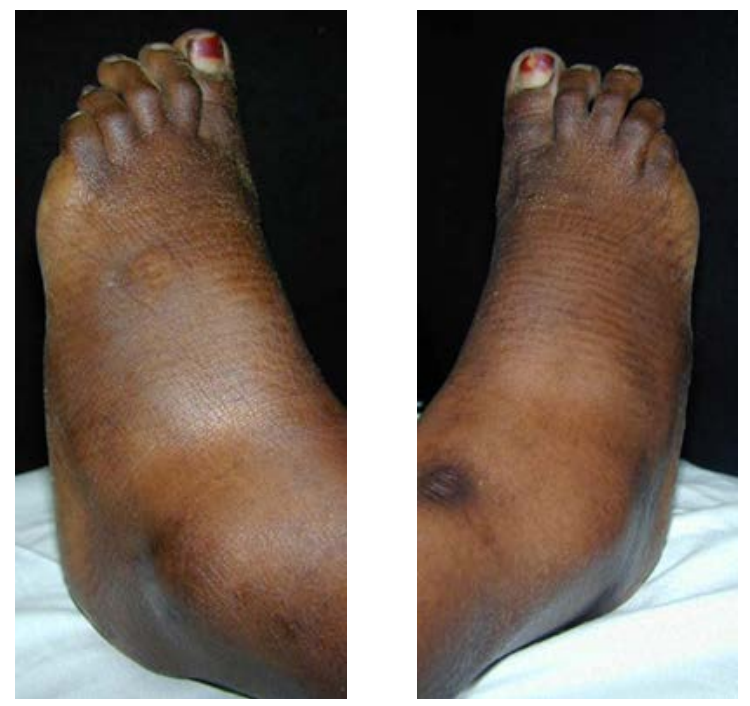

Figure 1. Clinical appearance, base swelling of the fifth metatarsals. 
under anesthesia spine and pneumatic tourniquet placed at the root of the member. The operating technique was identical for both sides. The approach was posterolateral curvilinear. The banks of the fracture were revived and the medullary canal re-stabilized (Figure 4 and Figure 5). After interposition of a spongy graft taken from the left iliac crest, screwing with a malleolar screw was performed. The post-operative radiographic checks were satisfactory (Figure 6 and Figure 7). The operating suites were simple. After a 9-month follow-up, a consolidation was obtained with painless feet allowing the patient to return to work.
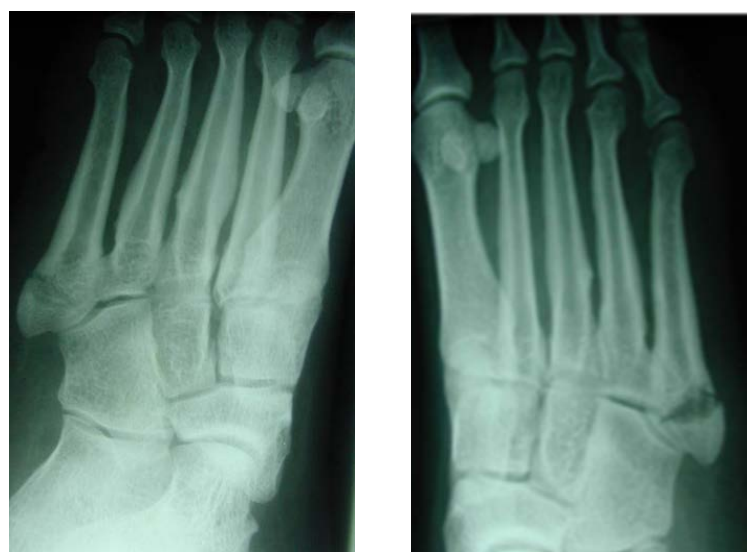

Figure 2. Radiographic aspects of lesions with tight non-union on the left and loose on the right.

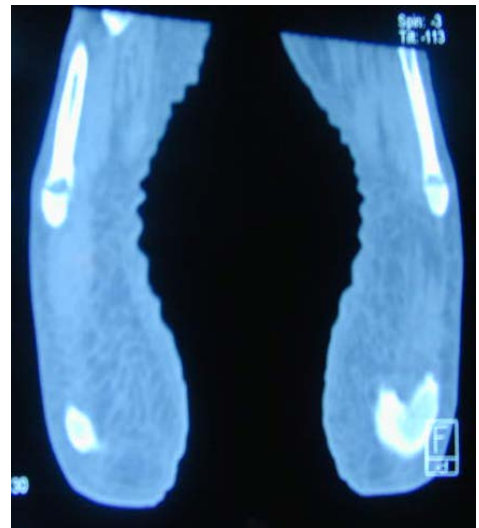

Figure 3. CT appearance of the two fracture sites.

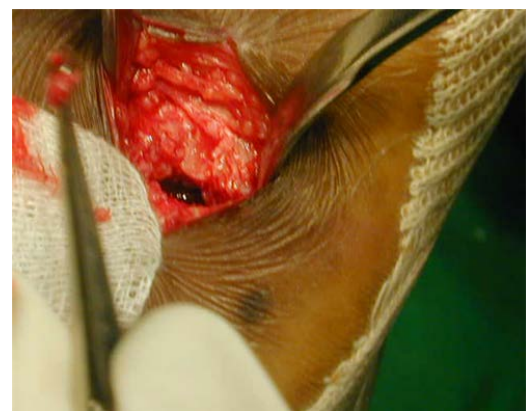

Figure 4. Intraoperative view of the pseudarthrosis focus on the right. 


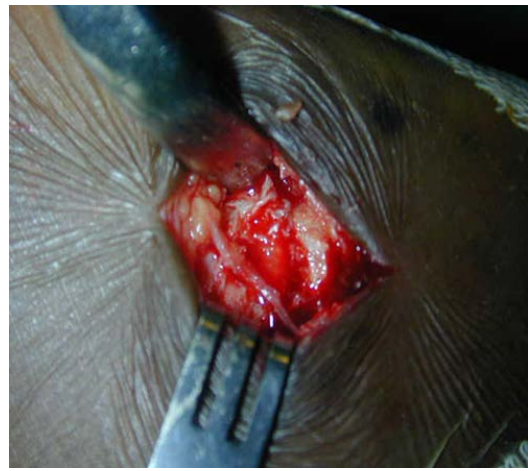

Figure 5. Intraoperative view of the pseudarthrosis focus on the left.

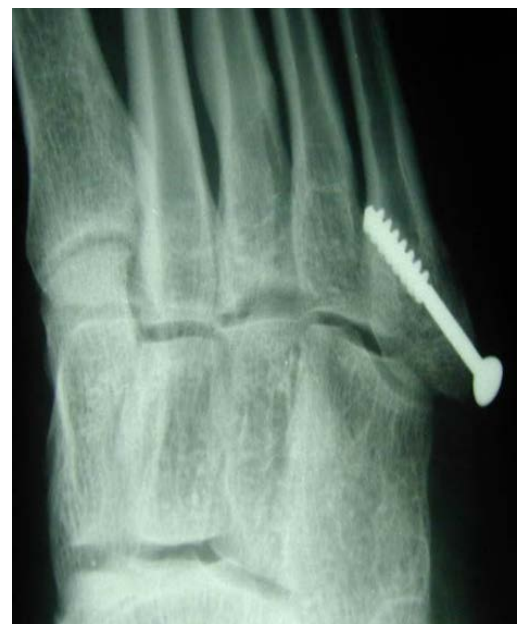

Figure 6. Post-operative control of reduction and fixation on the left.

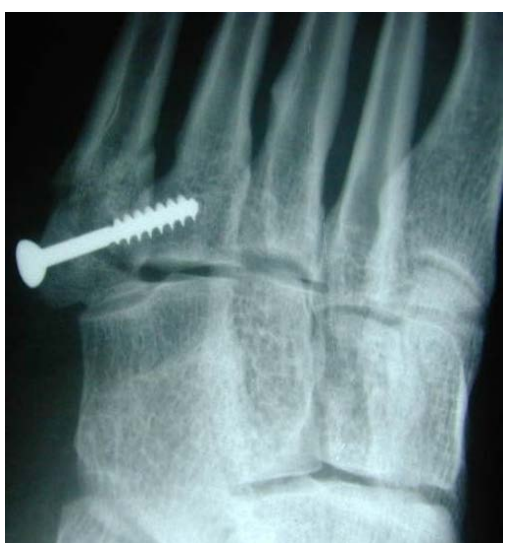

Figure 7. Post-operative check of reduction and fixation on the right.

\section{Discussion}

The fifth metatarsal has been identified as the most commonly fractured metatarsal except in children under 15 years of age [2] [3] [7]. The fracture of its base described by Sir Robert Jones in 1896 is the source of etiological, prognostic and therapeutic confusion [8]. This frequent fracture of the foot has been often studied in the military, athletes and the European population [7] [9] [10]. This le- 
sion is usually mono lateral, its occurrence on the 2 feet is an exception, few cases have been described in the literature. Smith [11] reports a post traumatic bilateral case. There are risk factors such as high body mass index, old age and diabetes. The postmenopausal female subject is often affected, due to the fall of estrogen. In general, osteoporosis increases the risk of fracture [12]. Singer and col. have demonstrated the high incidence of osteoporotic fractures in women from their fifties. By studying the results of the National Osteoporosis Risk Assessment (NORA), they clearly showed the relationship between low bone density and the relative risk of fracture [13] [14]. Our patient had several risk factors for stress fractures, namely menopause, overweight and osteoporosis. Indeed, post-cortisonic osteoporosis, conventionally a provider of micro fractures, and osteomalacia following the surgical castration of parathyroids with chronic hypocalcemia were selected as our main etiological factors unlike the case described by Smith [11] or a traumatic origin had been clearly found. The spontaneous or micro-trauma nature of the fracture was retained due to the bilateral aspect and the acquired bone fragility, even if minimal trauma was mentioned.

In 1960, Stewart defined the Jones fracture as a transverse fracture at the junction between the diaphysis and the metaphysis, with no distal extension to the inter metatarsal joint [15]. Later, the term "Jones fracture" was also used for diaphyseal fractures. Thus these two types of fractures were grouped under the name of "fractures of the base of the fifth metatarsal distal to the tuberosity" or "fractures involving the proximal part of the diaphysis distal to the tuberosity" [15] [16]. Due to the lack of differentiation between the real Jones fracture and the diaphyseal stress fracture, these two types of fracture are generally treated in the same way [17] [18]. TORG has identified three types of lesion since 1985: the avulsion fracture from the base in zone 1, the so-called Jones fracture in zone 2 to $1.5 \mathrm{~cm}$ from the metaphysis [19] [20], the metaphyso-diaphyseal fracture in zone 3 [15]. Our bilateral fracture was classified type 2 or Jones fracture.

The therapeutic management of this fracture remains controversial [4] [8]. Some authors have mentioned the difficulty of treating Jones fractures which very often progress to non-union linked to the precariousness of the vascularization [4]. In the literature these fractures are discovered at an earlier stage. Their treatment was mainly orthopedic by performing a plastered splint without loading for six to eight weeks [19] [20]. The operative indication is mainly asked in relation to the age of the fracture and the level of physical activity of the patient [20]. According to Bowes [21] surgical treatment is recommended if there is more than three to four millimeters of displacement or ten degrees of plantar angulation of the fractures and that a closed reduction is not sufficient. In athletes, bone fixation is done by intramedullary screwing or by a plate and allows to obtain a rapid consolidation and an early resumption of activities of almost $50 \%$ compared to orthopedic treatment [20] [22]. The fractures in our patient were diagnosed at the stage of tight non-union on the left and loose on the right. This stage of discovery is usual in our context after failure of traditional treatment. The treatment in our case was surgical by bone grafting and screwing unlike the case described by Smith. 


\section{Conclusion}

The bilateral fracture of the base of the fifth metatarsal remains a frequent lesion. The spontaneous nature and the failure or the delay of the consolidation and the bilaterality must always motivate the search for a non-traumatic etiological factor. The persistent symptomatic nature should make screwing with or without a bone graft preferable to conservative orthopedic treatment.

\section{Conflicts of Interest}

The authors declare no conflicts of interest regarding the publication of this paper.

\section{References}

[1] Petrizzi, M.J. and Reece, S.G. (1999) Fractures of the Proximal Fifth Metatarsal. American Family Physician, 1, 2516-2522.

[2] Armagan, O.E. and Shereff, M.J. (2001) Injuries to the Toes and Metatarsals. Orthopedic Clinics of North America, 32, 1-10. https://doi.org/10.1016/S0030-5898(05)70189-9

[3] Petrisor, B.A., Ekrol, I. and Court-Brown, C. (2006) The Epidemiology of Metatarsal Fractures. Foot \& Ankle International, 27, 172-174. https://doi.org/10.1177/107110070602700303

[4] Zwitser, E.W. and Breederveld, R.S. (2010) Fractures of the Fifth Metatarsal, Diagnosis and Treatment. Injury, 41, 555-562. https://doi.org/10.1016/j.injury.2009.05.035

[5] Anderson, M. and Greenspan, A. (1996) Stress Fractures. Radiology, 199, 1-12. https://doi.org/10.1148/radiology.199.1.8633129

[6] Daffner, R.H. and Pavlov, H. (1992) Stress Fractures/Current Concepts. AJR, 159, 245-252. https://doi.org/10.2214/ajr.159.2.1632335

[7] Singer, G., Cichocki, M., Schalamon, J., Eberl, R. and Höllwarth, M.E. (2008) A Study of Metatarsal Fractures in Children. The Journal of Bone and Joint Surgery. American Volume, 90, 772-776. https://doi.org/10.2106/JBJS.G.00547

[8] Ding, B.C., Weathearll, J.M., Mroczek, K.J., et al. (2012) Fractures of the Proximal Fifth Metatarsal: Keeping up with the Joneses. Bulletin of the NYU Hospital for Joint Diseases, 70, 49-55.

[9] Cakir, H., Van Vliet-Koppert, S.T., Van Lieshout, E.M., De Vries, M.R., Van Der Elst, M. and Schepers, T. (2011) Demographics and Outcome of Metatarsal Fractures. Archives of Orthopaedic and Trauma Surgery, 131, 241-245. https://doi.org/10.1007/s00402-010-1164-6

[10] Chuckpaiwong, B., Queen, R.M., Easley, M.E. and Nunley, J.A. (2008) Distinguishing Jones and Proximal Diaphyseal Fractures of the Fifth Metatarsal. Clinical Orthopaedics and Related Research, 466, 1966-1970. https://doi.org/10.1007/s11999-008-0222-7

[11] Smith, et al. (1997) Base of the Fifth Metatarsal Fractures, an Unusual Presentation. The Journal of the Royal Army Medical Corps, 143, 51-52. https://doi.org/10.1136/jramc-143-01-11

[12] Kanis, J.A., Burlet, N., Cooper, C., et al. (2013) European Guidance for the Diagnosis and Management of Osteoporosis in Postmenopausal Women. Osteoporosis International, 24, 23-57. https://doi.org/10.1007/s00198-012-2074-y 
[13] Singer, B.R., McLauchlan, G.J., Robinson, C.M. and Christie, J. (1998) Epidemiology of Fractures in 15,000 Adults: The Influence of Age and Gender. The Journal of Bone and Joint Surgery. British Volume, 80, 243-248. https://doi.org/10.1302/0301-620X.80B2.0800243

[14] Lehman, R.C., Torg, J.S., Pavlov, H. and DeLee, J.C. (1987) Fractures of the Base of the Fifth Metatarsal Distal to the Tuberosity: A Review. Foot Ankle, 7, 245-252. https://doi.org/10.1177/107110078700700406

[15] Stewart, I.M. (1960) Jones's Fracture: Fracture of Base of Fifth Metatarsal. Clinical Orthopaedics, 16, 190-198.

[16] Lawrence, S.J. and Botte, M.J. (1993) Jones' Fractures and Related Fractures of the Proximal Fifth Metatarsal. Foot Ankle, 14, 358-365. https://doi.org/10.1177/107110079301400610

[17] Quill, G.E. (1995) Fractures of the Proximal Fifth Metatarsal. Orthopedic Clinics of North America, 26, 353-361.

[18] Shereff, M.J., Yang, Q.M., Kummer, F.J., Frey, C.C. and Greenidge, N. (1991) Vascular Anatomy of the Fifth Metatarsal. Foot Ankle, 11, 350-353.

https://doi.org/10.1177/107110079101100602

[19] Smith, J.W., Arnoczky, S.P. and Hersh, A. (1992) The Intraosseous Blood Supply of the Fifth Metatarsal: Implications for Proximal Fracture Healing. Foot Ankle, 13, 143-152. https://doi.org/10.1177/107110079201300306

[20] Kakkar, R. and Akimau, P.F. (2010) Jones' Fracture of the Fifth Metatarsal Base or an Avulsion Fracture: Do We Really Need to Distinguish between Them. Injury, 7, 373. https://doi.org/10.1016/j.injury.2010.07.374

[21] Bowes, J. and Buckley, R. (2016) Fifth Metatarsal Fractures and Current Treatment. World Journal of Orthopedics, 7, 793-800. https://doi.org/10.5312/wjo.v7.i12.793

[22] Mologne, T.S., Lundeen, J.M., Clapper, M.F. and O’Brien, T.J. (2005) Early Screw Fixation versus Casting in the Treatment of Acute Jones Fractures. The American Journal of Sports Medicine, 33, 970-975. https://doi.org/10.1177/0363546504272262 